\title{
Practical Approach to Assessment of Effectiveness and Efficiency of Management Systems for Occupational Safety
}

\author{
Andrei Nikulin ${ }^{1 *}$, Irina Klimova ${ }^{2}$ and Eva Mrackova ${ }^{3,}$ \\ 1 Saint Petersburg Mining University, Saint Petersburg, Russia; nikulin an@pers.spmi.ru \\ 2 FGBOU VO “UGTU”, Ukhta, Russian; bgd4@mail.ru \\ 3 Technical University in Zvolen, Zvolen, Slovakia; mrackova@tuzvo.sk \\ * Correspondence: nikulin_an@pers.spmi.ru; Tel.: +7 9216428963
}

\begin{abstract}
This paper is focused on the analysis of methods used to assess effectiveness and efficiency of the occupational safety and health management system (OSHMS) in a company. It reviews current Russian and international occupational safety and health standards. The paper details the method outlined in International Standard GOST 12.0.230.3-2016 "Occupational safety standards system. Management systems for occupational safety. Evaluation of effectiveness and efficiency" based on the data collected during the external audit of OSHMS function efficiency in a Russian mining company. Effectiveness and efficiency indicators were determined, and a generalized desirability coefficient was calculated. Weaknesses of the method proposed in GOST 12.0.230.3-2016 were identified and mathematical and linguistic solutions were proposed to improve it. Harrington function was used to determine a numerical and linguistic score. The performed calculation demonstrated that the company needed strategic management decisions to improve the current situation. Practical approaches were offered to enhance the company's systems-based occupational safety and health performance..
\end{abstract}

Keywords: occupational safety, management systems for occupational safety, OSHMS, efficiency, effectiveness criterion, effectiveness indicator, generalized desirability indicator, Harrington function

\section{Introduction}

The systems-based approach to occupational safety and health management at the corporate level helps to achieve organizational, financial and economic and social effects resulting in improved production efficiency.

The first regulations covering systems-based management included in the standards developed by ISO (International Organization for Standardization) pertained to product quality (ISO 9000). Then in mid-1990s, ISO 14000 standards covering environmental management emerged. In 1999, OHSAS 18001:1999 was developed. It contained a model of an occupational safety and health management system (OSHMS). In 2001, the International Labor Organization (ILO) issued Guidelines on occupational safety and health management systems (ILO-OSH-2001), and in 2007, a new OHSAS version (OHSAS 18001:2007) was published. In March 2018, ISO 45001:2018 "Occupational health and safety management systems - requirements with guidance for use" developed by the International Organization for Standardization, took effect. This standard has a high-level structure that makes it possible to combine its requirements with those of ISO 9001:2015 and ISO 14001:2015. It is intended to solve the issue of low staff involvement in systems-based occupational safety and health management. The standard focuses on a risk-oriented approach aimed at preventing production accidents.

Therefore, the systems-based approach principle is uniform for all managed items, such as product quality, environment and occupational safety. An integral part of all management systems is a continuous improvement principle targeted at achieving specific goals [1]. 
Currently, the following main OSHMS regulations apply to a company in the Russian Federation: GOST 12.0.230-2007 "Occupational safety standards system. Occupational safety and health management systems. General requirements", GOST R 54934 - 2012/OHSAS 18001:2007 "Occupational health and safety management systems. Requirements", GOST R 12.0.007-2009 "Occupational safety standards system. Labor protection management system in organization. General requirements on development, implementation, audit and improvement", GOST R 12.0.0092009 "Occupational safety standard system. Occupational safety and health management systems in small organizations. Requirements and guidelines on implementation", GOST R 12.0.008-2009 "Occupational safety standards system. Occupational safety and health management systems in organizations. Audit", GOST R 12.0.010-2009 "Occupational safety standards system. Occupational safety and health management systems. Hazard and risks identification and estimation of risks", as well as the so called 230th GOST series: GOST 12.0.230.1-2015 "Occupational safety standards system. Occupational safety and health management systems. Guidance for use of GOST 12.0.230-2007", GOST 12.0.230.2-2015 "Occupational safety system standards. Occupational safety and health management systems. Conformity assessment. Requirements", GOST 12.0.230.3-2016 "Occupational safety standards system. Management systems for occupational safety. Evaluation of effectiveness and efficiency", GOST 12.0.230.4-2018 "Occupational safety standards system. Occupational safety and health management systems. Methods of hazards identification for various period of working", GOST 12.0.230.5-2018 "Occupational safety standards system. Health management systems. Risk assessment methods to ensure the safety of work", GOST 12.0.230.6-2018 "Occupational safety standards system. Health management systems. Ensuring compatibility of health management system with other management systems". We would like to remind that these standards are recommendations, but if the company's local regulations contain references thereto, their requirements become mandatory [2-7].

Practical experience shows that many employers do not have a clear and easy to use OSHMS effectiveness and efficiency assessment procedure in place. It is necessary to understand respective reasons and carefully review GOST 12.0.230.3-2016.

\section{Materials and Methods}

Traditional forms of corporate annual reporting on occupational safety and health include such indicators as: injury frequency rate, severity rate, labor loss indicator, etc. These corporate occupational safety assessment forms are an example of a post-event analysis with effectiveness indicators including such measures as reduced number of minor accidents from seven to five period over period. Therefore, when a company follows this logic and plans a reduction of the indicator from five to four accidents, it thus plans minor accidents (allows them under the plan). Practical experience shows that the companies, which deny the possibility of a Zero Accident Plan, are satisfied with planning for accidents and consider it normal [8-10]. The implementation of best occupational safety practices implies the use of "preventive compliance models" aimed at the prevention and forestalling of violations [11-12].

The assessment of occupational safety effectiveness is a multi-criteria challenge which can be handled using various methods to build a generalized indicator. One of such methods is Harrington generalized desirability function, which is characterized by continuity, monotony and evenness [13].

The principle of the assessment method using generalized Harrington function is to obtain a generalized indicator for an occupational safety status and conditions and use it to compare various OSHMS instead of using simple comparison of individual indicators that characterize effectiveness and efficiency [14-15].

The conversion of specific occupational safety effectiveness and efficiency indicators (PEI) into abstract numerical values is based on the use of Harrington "desirability curve", which is determined by a function (dimensionless numerical variable) with two saturation areas and a linear area.

The desirability scale is divided into five ranges within a 0 to 1 range. Proposed alignment between the ratios of preference in verbal (linguistic) and numerical systems is summarized in 
Table 1.

Table 1. Alignment between the linguistic and numerical systems of Harrington function

\begin{tabular}{cc}
\hline $\begin{array}{c}\text { Verbal (linguistic) } \\
\text { expression }\end{array}$ & $\begin{array}{c}\text { Value intervals of } \\
\text { Harrington function }\end{array}$ \\
\hline Very good & 0.80 to 1.00 \\
Good & 0.63 to 0.80 \\
Satisfactory & 0.37 to 0.63 \\
Bad & 0.20 to 0.37 \\
Very bad & 0.00 to 0.20 \\
\hline
\end{tabular}

The "desirability curve" changes slowly in the extreme scores area ("very good" and "very bad") and fast in the medium score area ("satisfactory"), which is typical for many safety, reliability and quality characteristics. Therefore, Harrington scale basically shows the nature of the distortion of expert assessments due to their subjectivity.

The PEI examples below are recommendations as per GOST 12.0.230.3-2016. The groups of indicators and individual specific indicators are not complete or exhaustive for all potential cases. It is not mandatory for a company to adopt each group or each indicator. The company must independently choose and develop PEI based on its policy and goals taking into account the specifics of its production operations, scale of its business units (number and remoteness), headcount, etc. Moreover, it has an option to use all, some or none of the PEI examples outlined below.

Most PEI examples are expressed as a share or percentage which is the best way to evaluate the idea and scale of a phenomenon. Other examples are expressed in quantities as a time unit or values per employee, per product unit or as other relative, generalized or weighted indicators, which simplifies the use of various PEIs [16-17]. Table 2 summarizes high-level groups of indicators involved in further assessment.

Table 2. Effectiveness and efficiency indicators of management (PEIM) for occupational safety

\begin{tabular}{c|c|c}
\hline Position & OSHMS element & $\begin{array}{c}\text { Number of } \\
\text { indicators }\end{array}$ \\
\hline 1 & Occupational safety policy & 6 \\
2 & Involvement of employees and their representatives & 6 \\
3 & Duties and accountability & 2 \\
4 & Competency and training & 16 \\
5 & OSHMS documentation & 3 \\
6 & Information transfer and exchange & 5 \\
7 & Planning, development and use of the OSHMS & 6 \\
8 & Occupational safety goals & 2 \\
9 & Preventive and regulating measures & 14 \\
10 & Change management & 4 \\
11 & Prevention of, readiness and response to industrial accidents & 8 \\
12 & Procurement & 3 \\
13 & Contracted work & 4 \\
14 & Effectiveness monitoring and assessment & 4 \\
15 & Investigation of job-related injuries, cases of health decline, & \\
& diseases and incidents and their impact on occupational & \\
16 & safety and health activities & 4 \\
17 & Inspection & 5 \\
18 & Analysis of OSHMS efficiency by management & 4 \\
19 & Preventive and corrective actions & 6 \\
\hline & Continuous improvement & 6 \\
\hline
\end{tabular}


OSHMS effectiveness was assessed based on three indicators:

1. Single indicator for the visual presentation of the ratio of "positive' and "negative" points, $E_{\Pi}$, in an interval from minus 1 for "everything is bad" (e.g., nothing is done) to plus 1 for "everything is good" (e.g., everything is done on time) (1):

$$
E_{\text {п }}=\frac{\left(n^{+}-n^{-}\right)}{\left(n^{+}+n^{-}\right)},
$$

where $n^{+}$is the number of positive points; $n^{-}$is the number of negative points.

2. Additive synthesizing function is a weighted arithmetic mean, $Q_{A}$, where each summed up individual $i$ th single indicator, $q_{i}$, is taken with a specific significance weight, $w_{i}(2,3)$ :

$$
\begin{aligned}
& Q_{\mathrm{A}}=\frac{\sum_{1} w_{i} q_{i}}{W}, \\
& W=\sum_{1} w_{i} .
\end{aligned}
$$

3. Multiplicative synthesizing function is a weighted geometric mean, $Q_{\Gamma}$, where each multiplied individual $i$ th single indicator, $q_{i}$, is taken with a specific significance weight, $w_{i}(4)$ :

$$
Q_{\Gamma}=\left(\begin{array}{c}
\prod q_{i}^{w_{i}} \\
{ }^{1 / W}
\end{array}\right.
$$

\section{Results}

Let us consider the proposed method for OSHMS effectiveness and efficiency assessment in more detail along with mathematical processing methods and data presentation for the indication (indicator calculation) of occupational safety effectiveness and efficiency outlined in the Appendix to GOST 12.0.230.3-2016.

The desirability indicator was calculated based on the case of a mining company. The OSHMS documents collected during external audit for a period between 2015 and 2019 enabled to define 48 indicators used to assess OSHMS effectiveness and efficiency.

The following indicators were calculated based on the results of that assessment: $Q_{A}=0.2118 ; Q_{I}$ $=0.0437 ; E_{\Pi}=-0.5379$.

The following changes were made to the mathematical calculation method:

1. The minus sign was added to the formula for $d$ function before the second function of "exp": $d=$ $\exp [-\exp (-Y)]$ to replace $d=\exp [\exp (-Y)]$.

2. $E_{\Pi}$ indicator, which is cardinally different from two others, was converted into [0;1] range and amounted to 0.231 . The interpolation of $E_{\Pi}$ indicator is shown in Figure 1. This section may be divided by subheadings. It should provide a concise and precise description of the experimental results, their interpretation as well as the experimental conclusions that can be drawn. 


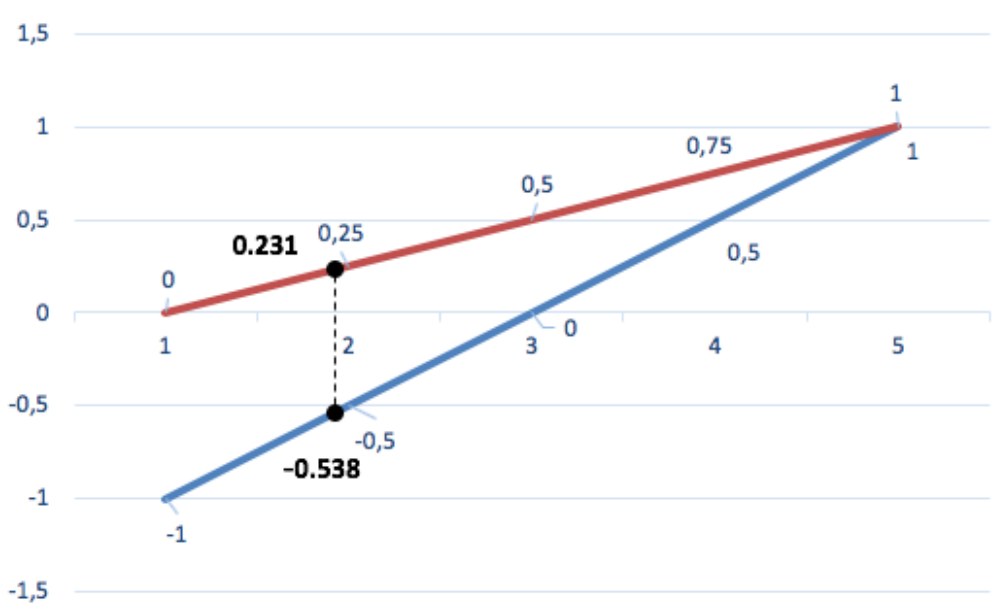

Figure 1. The interpolation of $E_{\Pi}$

3. The description and alignment limits of the linguistic and numerical systems of Harrington function were adjusted (Table 3 ).

Table 3. New (author's version) of alignment between the linguistic and numerical systems of Harrington function

\begin{tabular}{cc}
\hline Linguistic assessment & Score on the scale \\
\hline Excellent & $0.80 \leq \mathrm{D}<1.00$ \\
Good & $0.63 \leq \mathrm{D}<0.80$ \\
Acceptable & $0.37 \leq \mathrm{D}<0.63$ \\
Bad & $0.20 \leq \mathrm{D}<0.37$ \\
Dangerous & $0.00 \leq \mathrm{D}<0.20$ \\
\hline
\end{tabular}

The desirability function reflects the dependence of assessments (or desirability indicators $(d)$ on dimensionless indicators $(y)$, dimensional (natural) quality indicators are converted into. This relationship is expressed in the following formula:

$$
d=\exp [-\exp (-Y)]
$$

Generalized desirability indicator $(D)$ is calculated using the formulas below:

- without weight factors applied:

$$
D=\sqrt[n]{\prod_{i}^{n} d_{i}}
$$

- with weight factors applied:

- where mi is a weight factor.

$$
D=\prod_{i}^{n}\left(d_{i}\right)^{m_{i}}
$$

The accuracy of the overall assessment increases with weight factors applied.

The following formula (8) can be used to convert dimensional (natural) indicators $(x)$ into dimensionless ones $(y)$ if there is linear dependence between the same:

$$
Y=a_{0}+a_{1} \cdot x
$$

if we take the logarithm twice (5), we obtain:

$$
\ln (\ln (1 / d))=-y
$$

and make a set of equations: 


$$
\left\{\begin{array}{l}
a_{0}+a_{1} \cdot x_{1}=-\ln \left(-\ln \left(d_{1}\right)\right) \\
a_{0}+a_{1} \cdot x_{2}=-\ln \left(-\ln \left(d_{2}\right)\right)
\end{array}\right.
$$

By solving both equations, we can define values for a 0 and a1 coefficients. The result is a linear dependence equation between the studied indicator and dimensionless values. This equation can be used to define $y$ value for any $x$ value and then use formula (5) to calculate the desirability indicator.

Let us take $\mathrm{d}_{1}=0.7$ ("good"), $\mathrm{d}_{2}=0.2$ ("bad"). Then, taking into account (10):

$$
\left\{\begin{array}{c}
a_{0}+a_{1} \cdot x_{1}=1,03 \\
a_{0}+a_{1} \cdot x_{2}=-0,48
\end{array}\right.
$$

With (11), using $x_{1}$ and $x_{2}$ values corresponding to "good" and "bad" scores, we will calculate numerical values of $a_{0}$ and $a_{1}$ for all indicators.

$Q_{A}=Q_{\Gamma}=E_{\Pi}=1$ for maximum values and $Q_{A}=Q_{\Gamma}=E_{\Pi}=0$ for minimum values.

Solution of the set of equations for three indicators:

$$
\left\{\begin{array}{c}
a_{0}+a_{1}=1,03 \\
a_{0}=-0,48
\end{array}\right.
$$

Then $a_{1}=1.03-a_{0}=1.03+0.48=1.51$.

We will determine $y_{i}$ for $Q_{A}, Q_{\Gamma}$ and $E_{\Pi}$ :

$y_{i}\left(Q_{A}\right)=-0.16018 ; y_{i}\left(Q_{\Gamma}\right)=-0.41401 ;$ and $y_{i}\left(E_{\Pi}\right)=-0.13119$.

We will determine partial desirability indicators, $d_{i}$, using formula (5) as follows:

$d\left(Q_{A}\right)=0.3092 ; d\left(Q_{\Gamma}\right)=0.2203 ;$ and $d\left(E_{\Pi}\right)=0.3198$.

Using formula (6), we will determine the generalized desirability indicator of $D=0.2793$, which corresponds to the linguistic score of "bad" (Figure 2).

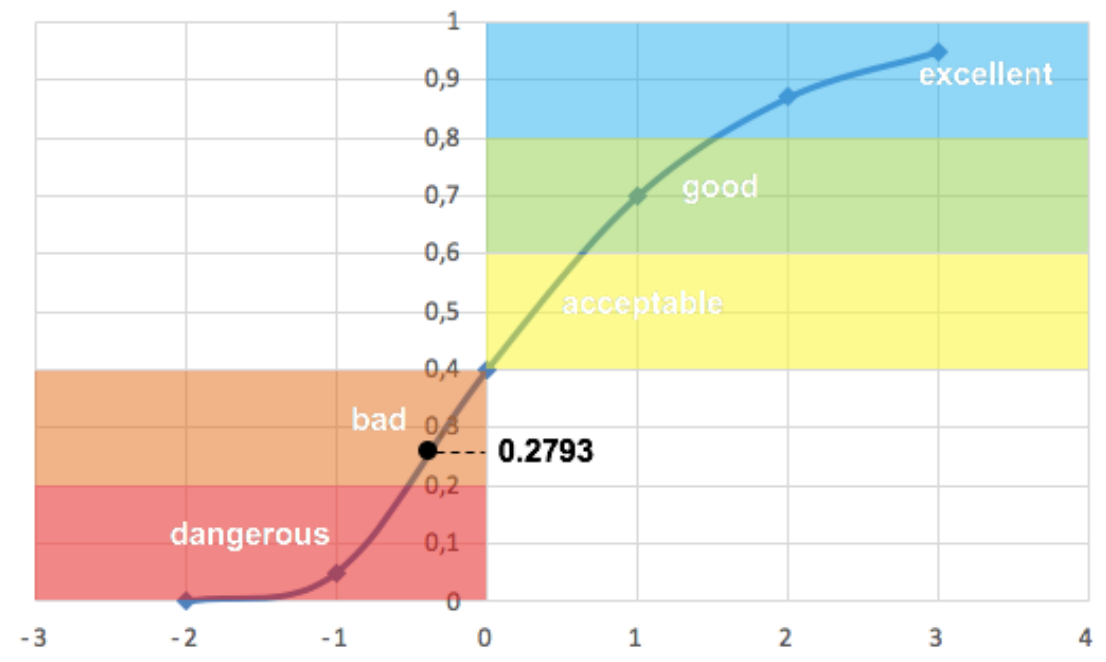

Figure 2. Illustration of Harrington function

The performed assessment of OSHMS effectiveness and efficiency in the company demonstrates a fairly true picture of the current OSHMS status. However, it should be noted that selected indicators, their assessment and weight coefficients have an expert impartial level of measurement. In a real production process, employees responsible for occupational safety can "adjust" the indicators to meet a required desirability level. However, the use of the indicators presented in GOST 12.0.230.3-2016 or those developed by the company is not an efficient process anymore and does not efficiently define the company's occupational safety goals and objectives or implement the continuous improvement principle [18-19]. 
It is crucial to secure the involvement of top management in expert use of the indicators and their weight coefficients since top management influences the allocation of financial, organizational and other resources needed for OSHMS improvement [20-21].

The important result of effectiveness and efficiency assessment is possibility to compare individual indicators and desirability indicators in general both in structural units and in subsidiaries. And if we go beyond a company, we can easily implement occupational safety benchmarking principles. (Benchmarking is a process of continuous survey of best practices, which determine the highest characteristic of competitiveness) [22-23].

The presented OSHMS effectiveness and efficiency assessment method in the company pursuant to GOST 12.0.230.3-2016 is not the only possible tool to be used to organize this work. It is however considered a fairly functional tool to build a continuous improvement procedure for occupational safety.

\section{Discussion}

The performed assessment of OSHMS effectiveness and efficiency in the company demonstrates a fairly true picture of the current OSHMS status. However, it should be noted that selected indicators, their assessment and weight coefficients have an expert impartial level of measurement. In a real production process, employees responsible for occupational safety can "adjust" the indicators to meet a required desirability level. However, the use of the indicators presented in GOST 12.0.230.3-2016 or those developed by the company is not an efficient process anymore and does not efficiently define the company's occupational safety goals and objectives or implement the continuous improvement principle [18-19].

It is crucial to secure the involvement of top management in expert use of the indicators and their weight coefficients since top management influences the allocation of financial, organizational and other resources needed for OSHMS improvement [20-21].

The important result of effectiveness and efficiency assessment is possibility to compare individual indicators and desirability indicators in general both in structural units and in subsidiaries. And if we go beyond a company, we can easily implement occupational safety benchmarking principles. (Benchmarking is a process of continuous survey of best practices, which determine the highest characteristic of competitiveness) [22-23].

The presented OSHMS effectiveness and efficiency assessment method in the company pursuant to GOST 12.0.230.3-2016 is not the only possible tool to be used to organize this work. It is however considered a fairly functional tool to build a continuous improvement procedure for occupational safety.

\section{Conclusions}

Current international and Russian regulatory occupational safety documentation stipulates not only the need to have OSHMS in place in a company but also the need to develop a tool for its continuous improvement. The OSHMS internal and external audits practiced facilitate the identification of deviations in its functioning. However, there are rather large intervals between these audits of one to three years. The proposed improved method for OSHMS effectiveness and efficiency assessment will help to do this more frequently, in an easier and more cost-effective way.

Main practical recommendations for a company manager (manager of a mining company):

1. Systematize the process of OSHMS effectiveness and efficiency assessment, which can be done by creating software based on the mathematical tools presented above.

2. Make the assessment and re-verification of the current occupational safety status more objective (compare with traditional indicators).

3. Update occupational safety improvement and development plans and programs.

4. Make it possible to use integrated assessment of the whole range of indicators (their generalization), as well as specific indicators, which are not used in common methods, and most 
importantly use them with a weight coefficient, which is also extremely relevant in professional risk assessment procedures.

5. The authors believe that the most significant benefit of this approach is the possibility of the full-scale combination of the professional risk assessment procedure implemented in the company and OSHMS efficiency assessment procedure. They have common numerical and linguistic characteristics so that they can be combined, compared and complemented for their joint use and it certainly enables adjustment of corporate improvement plans and programs.

The list provided herein is not exhaustive as the proposed approach is flexible and deeply involved occupational safety employees led by company management can expand and adjust it within company-specific challenges.

Conflicts of Interest: The authors declare no conflicts of interest.

\section{References}

1. 1. Rudakov, M.L.; Kolvakh, K.A.; Derkach, I.V. Assessment of environmental and occupational safety in mining industry during underground coal mining. Journal of Environmental Management and Tourism. 2020, 11(3), pp. 579-588. DOI: $10.14505 /$ jemt.v11.3(43).10

2. Chemezov, E.N. Industrial safety principles in coal mining. Journal of Mining Institute. 2019, 240, pp. 649653. DOI:10.31897/PMI.2019.6.649.

3. Nikulin, A.; Nikulina, A.Yu. Assessment of occupational health and safety effectiveness at a mining company. Ecology, Environment and Conservation. 2017, 23(1), pp. 351-355.

4. Kretschmann, J.; Plien, M.; Thi Hoai Nga, Nguyen; Rudakov, M. Effective capacity building by empowerment teaching in the field of occupational safety and health management in mining. Journal of Mining Institute. 2020, 242, pp. 248-256. DOI:10.31897/PMI.2020.2.248.

5. Karnachev, I.P.; Levashov, S.; Shkrabak, R.V.; Cheltybashev, A.A. Concept of occupational safety and health management in the Russian industry. Gornyi Zhurnal. 2018, 4, pp. 87-92. DOI: 10.17580/gzh.2018.04.16.

6. Vasilenko, N.; Khaykin, M.; Kirsanova, N.; Lapinskas, A.; Makhova, L. Issues for development of economic system for subsurface resource management in Russia through lens of economic process servitization International Journal of Energy Economics and Policy. 2020, 10(1), pp. 44-48. DOI: 10.32479/ijeep.8303

7. Lapshina, P.D.; Kurilova, S.P.; Belitsky, A.A. Development of an Arduino-based CO2 Monitoring Device. Proceedings of the 2019 IEEE Conference of Russian Young Researchers in Electrical and Electronic Engineering, ElConRus. 2019, pp. 595-597. DOI: 10.1109/EIConRus.2019.8656915.

8. Klimova, E.; Semeykin, A.; Nosatova, E. Improvement of processes of professional risk assessment and management in occupational health and safety system. IOP Conference Series: Materials Science and Engineering. 2016. DOI:10.1088/1757-899X/451/1/012198.

9. Koshy, K.; Preustti, M.; Rosen, M. Applying an Error Reduction Model to an Injury and Illness Prevention Programs- Steps to Improve an Occupational Safety and Health Management System (OSHMS). Journal of Management Research. 2019, 11(1). DOI:10.5296/jmr.v11i4.10775.

10. Manuele, F. Effective safety and health management systems. Chapter 22: Management roles and responsibilities. 2019, pp. 671-690. DOI:10.1002/9781119581482.ch22.

11. Opekunov, A.Yu.; Opekunova, M.G. Integral assessment of landscape pollution using the Harrington desirability function. Bulletin of Saint Petersburg University. 2014, 7(4), pp. 101-113.

12. Katuntsov, E.V.; Kultan, J.; Makhovikov, A.B. Application of electronic learning tools for training of specialists in the field of information technologies for enterprises of mineral resources sector. Journal of Mining Institute. 2017, 226, pp. 503-508.

13. Harington, J. The Desirability Function. Industrial Quality Control. 1965, 21(10), pp. 494-498.

14. Akhnazarova, S.L.; Gordeev, L. S. Use of the Harrington desirability function in solving optimization problems of chemical technology: textbook-met. manual. Moscow: D. I. Mendeleev Russian state technical University, 2003. 76 p.

15. Pichkalev, A.V. Generalized Harrington desirability function for comparative analysis of technical means. Research of the science city. 2012, 1, pp. 25-28.

16. Pashkevich, N.V.; Tarabarinova, T.A.; Golovina, E.I. Problems of reflecting information on subsoil assets in International Financial Reporting Standards. Academy of Strategic Management Journal. 2018, 17(3), pp. 1-9. 
17. Nikulina, A.Y.; Kruk, M.N. Organizational and economic mechanism of oil and gas projects in the Russian arctic shelf. Journal of Internet Banking and Commerce. 2016, 21(Special Issue 6), pp. 1-12.

18. Ngubo, S.; Kruger, C.; Hancke, G., Silva, B. An occupational health and safety monitoring system. Conference: IEEE 14th International Conference on Industrial Informatics (INDIN). 2016, Pp. 966-971. DOI: 10.1109/INDIN.2016.7819301.

19. Ratar, E.; Denny, H.; Rahfiludin, M.A. Comparative Analysis between Integrated Occupational Safety and Health Management System in a Support Mining Company and the Indonesian Mining Safety Management System. Indian Journal of Public Health Research and Development. 2018, 10(3):904.

20. Tripathy, D. Occupational Health and Safety in Mines. Mine Safety Science and Engineering. 2019. DOI: 10.1201/9781315162294-8.

21. Vasilkov, Y.; Gushina, L. Analysis of the effectiveness and efficiency of management systems based on system analysis methodology. International Journal for Quality Research. 2014, 8, pp. 347-356.

22. Nefedov, Y. The Arctic Shelf and Hard to Recover Oil Reserves as Alternative Development of Russian Resource Base. Conference Proceedings. Saint Petersburg 2018, Apr 2018, Volume 2018, pp.1 - 6. DOI: 10.3997/2214-4609.201800313.

23. Vasilev, Y.; Vasileva, P.; Tsvetkova, A. International review of public perception of CCS technologies. International Multidisciplinary Scientific GeoConference Surveying Geology and Mining Ecology Management. 2019, 19(5.1), pp. 415-422. DOI: 10.5593/sgem2019/5.1/S20.052 